\title{
A escola como entidade promotora de melhoria da convivência, através da mediação de conflitos, no contexto das ciências da educação
}

\author{
The school as a promoter of improvement of social coexistence, through the \\ mediation of conflicts, in the context of educational sciences
}

Elisabete Guedes Pinto da Costa

Doutora em Educação, pela Universidade Lusófona de Humanidades e Tecnologias. Investigadora do Centro de Estudos Interdisciplinares em Educação e Desenvolvimento e Diretora do Instituto de Mediação da Universidade Lusófona do Porto (OPO), Portugal (PT) elisabete.pinto.costa@ulp.com

Resumo: Os temas sobre os quais versa este artigo contribuem para identificar como o conflito, a convivência e a mediação escolar são elementos de estudo no campo das Ciências da Educação e em que medida a Escola atual pode construir-se como um espaço (social, cultural, organizacional e simbólico) para colocar em prática estratégias de intervenção de melhoria do seu contexto social e educativo, através de projetos de mediação de conflitos. A estratégia argumentativa tecida ao longo do artigo apoiou-se numa metodologia de pesquisa qualitativa, tendo como referência uma revisão de literatura das áreas em questão, que contribuiu para a construção e análise de categorias, conceitos e teorias que sustentam uma abordagem teórica da convivência escolar no nível meso da escola e no amplo alcance da mediação.

Palavras-chave: Convivência. Conflito. Mediação. Ciências da Educação.

Abstract: The topics covered by this article contribute to identify how conflict, coexistence and school mediation are elements of study in the field of Educational Sciences and to what extent the current School can be built as a (social, cultural, organizational and symbolic) space to implement strategies to improve their social and educational context, through projects of conflict mediation. The argumentative strategy woven throughout the article was based on a methodology of qualitative research, having as a reference a review of the literature of the areas in question, which contributed to the construction and analysis of categories, concepts and theories that support a theoretical approach to school coexistence at the meso level of the school and in the broad scope of mediation.

Keywords: Coexistence. Conflict. Mediation. Educational Sciences.

\section{Introdução}

O estudo sobre os conflitos, a convivência e a mediação tem conquistado o seu enquadramento na investigação das Ciências da Educação, onde a própria Escola é objeto de estudo e de intervenção. A Escola desempenha um papel extremamente importante no fomento de seres conscientes, críticos e criativos, que participam e estão comprometidos 
com o processo do seu próprio desenvolvimento (PINTO da COSTA e SÁ, 2019). Esta constitui, tal como os sujeitos da comunidade educativa, um ator aprendente, uma unidade de mudança e um pilar central da melhoria (BOLÍVAR, 2000; 2003). Reconhece-se que qualquer intervenção pela mudança e melhoria coloca em causa a clássica gramática organizacional da escola (CANÁRIO, 2010).

Partindo da problemática apontada, o objeto de pesquisa deste artigo versa sobre o estudo do conflito, da convivência e da mediação nas Ciências da Educação e na Escola. Mais especificamente, a proposta argumentativa adotada parte da seguinte questão de pesquisa: de que forma se pode enquadrar o estudo sobre o conflito, a convivência e a mediação de conflitos na pesquisa em Ciências da Educação e na Escola? E assume-se como objetivo principal do estudo sustentar um campo de análise e uma abordagem teórica para o estudo sobre o conflito, a convivência e a mediação de conflitos nas Ciências da Educação e na Escola. Para o efeito, propõe-se um modelo de revisão de literatura orientado numa perspetiva de análise de cariz qualitativa, sob uma estratégia indutiva, através da qual se estabelecem "conceitos sensibilizadores" para abordar os contextos sociais que se quer estudar" (FLICK, 2005, p. 2).

\section{0 conflito e a convivência na Escola como objeto de estudo}

Identificam-se na revisão da literatura contribuições de natureza diversa sobre a escola, tendo-se afirmado como objeto de estudo em diversos campos de ação, entre os quais, como refere SANCHES (2009, p. 5), aquelas que “(...) concetualizam e examinam os princípios, as finalidades e os valores que dizem respeito à escola enquanto espaço social". Este conceito de espaço social reporta para uma comunidade de complexas relações entre indivíduos, interdependentes, e com a organização, depositária e produtora de normas que regulam os espaços e os tempos das diversas interações que ocorrem no seu contexto.

A preocupação das escolas com problemas de convivência tem sido proporcional ao aumento dos vários tipos conflitos (cuja tipologia é elencada por CUNHA; MONTEIRO, 2018) e que prejudicam o seu ambiente social. Para além das perturbações à socialização que possam ocorrer no espaço escolar, verificam-se, cumulativamente, efeitos negativos ao nível da relação ensino-aprendizagem, afetando o exercício das funções do professor e do aluno, colocando em causa a eficácia da sala de aula e, em geral, da própria escola (AMADO; FREIRE, 2009). 
A sala de aula deixou de constituir, somente, o espaço, onde tudo se passa e de onde resultam quase todos os estudos de pesquisa. Como refere NÓVOA (1995), depois de uma abordagem que privilegia o nível micro, da sala de aula, ou o nível macro, do sistema educativo, emergiu uma sociologia das organizações escolares que se propõe optar por um nível meso de compreensão e de intervenção.

Ora, circunscrever os problemas que os conflitos acarretam às dinâmicas desenvolvidas dentro da sala de aula, implica excluir todo um universo de relações e de espaços que fazem parte da escola e, onde se pode levar a cabo intervenções socioeducativas promissoras, como é o caso da mediação de conflitos, e que podem apoiar o desenvolvimento de políticas internas de gestão da convivência.

\section{A convivência escolar como questão socioedutiva essencial da Escola}

A Escola é um espaço social, relacional e cultural, onde coabitam e convivem diversas personalidades, como professores, pessoal não docente, alunos e encarregados de educação, cada um com as suas experiências, motivações, pontos de vista, desejos e interesses. Como menciona TORREGO (2006, p. 19), “a convivência na escola quer-se pacífica e $[. .$.$] esta deve reconhecer a existência do conflito”. A convivência pacífica existe$ quando não se reprimem ou ignoram os conflitos, mas antes quando se lida com tais situações recorrendo a habilidades, estratégias e procedimentos adequados, assentes no diálogo, na colaboração e na responsabilização. Assim, como defende BRANDONI (2018, p. 63), "a aprender a conviver com os demais transformou-se numa das tarefas essenciais da escola [...] e é um dos conteúdos significativos que a escola deve ensinar".

Num ensaio sobre a convivência, GIMÉNEZ (2005, pp. 7-8) sustenta que “[...] esta palavra tem sempre uma conotação positiva e está carregada de ilusão, de projeto e de busca $[\ldots]$ encontrando de interesse para a análise do termo tanto o elemento relacional [...] como a referência à harmonia". O autor citado aponta ainda que a convivência, como interação, requer aprendizagem por parte dos indíviduos. A convivência é uma arte a apender e compreende, basicamente, quatro dimensões: normativa, atitudinal, identitária e regulação de conflitos que não encerra uma visão carente de conflito e de mudança. Ora, a oposição básica não será entre convivência e violência, mas entre convivência e não convivência. Daí que se possa questionar se uma escola onde não se verifiquem episódios de violência será um contexto de sã convivência. 
A convivência e a educação para a paz são termos que têm vindo a aparecer, desde a década de noventa, em diversos documentos oficiais da UNESCO(1) e do Conselho da Europa(2), e mais recentemente das Nações Unidas(3) ou da União Europeia(4). Geralmente, a convivência é comummente percecionada numa aceção negativa, ou seja: perante a existência de conflitos e o mau ambiente interacional não há uma convivência harmoniosa. Já numa aceção positiva da convivência, de algo a construir e a prosseguir, importa cuidar dos fatores que permitam expectar essa "[...] melhor situação e a ideal a alcançar" (GIMÉNEZ, 2005, p. 13). O autor que seguimos como referência indica-nos três contextos sociais onde a paz pode ou não existir: "[...] na hostilidade não há paz, na coexistência há uma paz negativa, e na convivência há uma paz positiva" (GIMÉNEZ, 2005, p. 13). Por sua vez, o autor advoga que se pode encontrar uma combinação destes elementos convivenciais numa determinada realidade social, percepcionada, tanto nas cognições e nas atitudes, como nas condutas e nos comportamentos, tomando-se "[...] a convivência como ideal social, a coexistência como algo muito valioso mas insuficiente e melhorável, e a hostilidade como algo a superar" (GIMÉNEZ, 2005, p. 13). Como última ideia deste ensaio ressalta-se que a busca por uma sã convivência não deverá tornar-se numa estratégia de dissuasão ou de conservadorismo, assente num discurso carente de crítica e ausência de ação transformadora.

\section{O conflito como oportunidade de melhoria da convivência escolar}

A dinâmica entre cenários relacionais, apresentados anteriormente, pressuporá uma mudança em relação à noção clássica do conflito (numa aceção negativa), que ocorre naturalmente entre os indivíduos nos mais diversos contextos sociais.

Não obstante, a democracia, a cidadania e a participação exporem mais os conflitos nas interações sociais, no caso particular da Escola mantém-se uma visão conservadora, arcaica e obsoleta do conflito. Para um melhor entendimento sobre o conflito em Educação considera-se necessário introduzir os três grandes paradigmas apresentados por JARES (1997, 2002): a visão tecnocrática-positivista, a visão hermenêutico-interpretativa e a visão crítica.

Segundo a perspetiva tecnocrática-positivista, a presença do conflito é negativa, se não mesmo sinal de algo disfuncional, em que a eficácia de um grupo ou organização é sinónimo de consenso. A capacidade de promover os consensos pressupõe evitar os conflitos, silenciar as diferenças e exercer um controlo sistemático. Nesse sentido, há que 
reprimir, ocultar ou evitar os conflitos. De acordo com a perspetiva hermenêuticainterpretativa, no conflito relevam-se as singularidades das situações, condicionadas pela interpretação particular de cada indivíduo, membro de um grupo ou organização. O conflito serve para motivar e estimular a criatividade individual ou grupal e a sua existência deve-se à perceção de cada sujeito. Já nos termos da perspetiva crítica, o conflito é assumido como algo natural e inerente às relações sociais e deve ser aproveitado como um mecanismo de mudança e transformação. Desta forma, para esta perspetiva teórica, não só se aceita o conflito como se favorece a sua gestão através do empoderamento dos indivíduos. Esta nova perspetiva abre a possibilidade de trabalhar estes momentos segundo uma abordagem transformativa, cruzando-se com a própria visão crítica de Educação. Neste sentido, os membros da comunidade educativa devem reconhecer no conflito um forte potencial educativo.

Em consequência, e retomando a análise em curso, os trabalhos sobre o conflito na Escola podem e devem ir para além do contexto da sala de aula. Contudo, à semelhança de outras áreas de pesquisa, também no que respeita ao conflito e à convivência, a Escola não surgiu desde logo como um contexto de análise, de estudo e de intervenção. JARES (2002, p. 85) propõe que o conflito deve ser “[...] objeto de análise e investigação prioritária, tanto na construção do corpo teórico da organização escolar como para facilitar o desenvolvimento organizacional das escolas".

A afirmação de novas teorias sobre o conflito, de novos modelos de abordagem ao conflito e, consequentemente, de modelos de regulação e promoção da convivência no seio escolar exigem, antes de mais, uma escola profundamente reflexiva como base para a mudança.

\section{Uma proposta de meso abordagem (orgânico-cultural) de análise e de intervenção}

A par dos estudos sobre o conflito na sala de aula, tendo em conta diferentes áreas disciplinares, como a psicologia e as ciências da educação, outros estudos foram surgindo no domínio da sociologia da Escola e da administração escolar. Importa, por isso, dar espaço a uma nova área de análise, onde as questões do conflito e da convivência se mostram cruciais para a organização escolar e sobre as quais não só se tem inovado muito pouco como a investigação é ainda escassa.

$[\ldots]$ os estudos centrados nas caraterísticas organizacionais das escolas tendem a construir-se com base em três grandes áreas: a estrutura fisíca da escola; a estrutura administrativa da escola e a estrutura social da escola (NÓVOA, 1995, p. 23). 
É nesta última grande área que se pode incluir a temática em questão, do conflito e da convivência escolar, porquanto esta reporta-se às seguintes dimensões da estrutura social: interação entre alunos, professores e funcionários, responsabilização e participação dos pais, democracia interna, cultura organizacional da escola, clima de escola.

Assim, analisar o modo como a Escola lida com o conflito e como se organiza para melhor responder aos desafios da conflitualidade, em prol de uma melhor convivência, enaltecendo a sua função educadora e socializadora, significa investigar e intervir na sua estrutura social.

No que diz respeito aos diversos estudos sobre a Escola, na abordagem organizacional, podem identificar-se, segundo TORRES e PALHARES (2010, p. 135), três principais focalizações teóricas: as macro-abordagens, as meso-abordagens e as microabordagens. Para cada uma dessas focalizações teóricas da sociologia da Escola, os autores apontam uma identificação e apreciação crítica, que aqui se resume:

As macro-abordagens de estudo sobre a Escola estão concentradas nas dinâmicas do sistema educativo e nas orientações da política educativa, tanto nacional como internacional. Sustentam os autores em questão que nesta dimensão os estudos procuraram analisar a Escola segundo os seguintes determinantes centrais: modelo político, modelo organizativo e funções do sistema educativo, descartando dessa forma a investigação de outras realidades escolares.

As micro-abordagens focam-se no estudo de fenómenos de interação de individuos, grupos ou subgrupos. Neste nível de análise “[...] a escola prefigura-se como um mero patamar intermédio, pretensamente neutro e incapaz de se impor como contexto específico e pertinente de investigação” (TORRES; PALHARES, 2010, p. 135). Aliás, este "[...] estudo de pequenas parcelas da realidade escolar [...] quase sempre insularizadas do contexto organizacional e político, também não consolidou, per si, um quadro abrangente da organização escolar" (TORRES; PALHARES, 2010, p. 135).

A distância entre as micro e macro abordagens remontam aos anos 70 e não reconheciam ou assumiam a Escola como "variável heuristicamente pertinente" (TORRES; PALHARES, 2010, p. 135). Foi na sequência do maior interesse pelo estudo das organizações escolares, tomando-a como "[...] uma verdadeira entidade dotada de uma autonomia relativa na produção normativa e cultural" (TORRES; PALHARES, 2010, p. 136), que se começou a encontrar outros estudos referentes a outros níveis de análise da Escola, deslocando-se a investigação para as meso-abordagens, que compreendem um olhar para as dinâmicas organizacionais, ou ainda para uma articulação entre os diferentes 
níveis de análise sobre a escola como organização social: macro, meso e micro. Pode-se apresentar como exemplos da abordagem macro-meso: a "[...] compreensão dos efeitos das políticas educativas de âmbito nacional e internacional (nível macro), no processo de regulação da vida quotidiana das escolas (nível meso)"; da abordagem micro-meso: o estudo de "[...] dimensões organizacionais da escola e a sua relação com as funções sociais desta instituição $[\ldots]$ ", sendo que aqui parte-se de um enfoque “[...] sobre um determinado espaço-tempo da escola (plano micro) para explorar os seus reflexos no funcionamento da organização (plano meso) (TORRES; PALHARES, 2010, p. 141).

Tradicionalmente, os estudos sobre o conflito $\mathrm{e}$ as relações interpessoais encaixavam-se, sobretudo, nas micro-abordagens. Mais recentemente, estes têm-se deslocalizado para as meso-abordagens ou numa combinação articulada dos planos micromeso da escola. Trata-se do estudo de fenómenos de interação de indivíduos, grupos ou subgrupos e respetivo enquadramento das decisões/ações tomadas ao nível da organização Escola. Um exemplo da articulação entre o plano micro-meso para estas questões de análise pode ser ilustrada da seguinte forma:

[...] ao contexto organizativo e cultural da escola como âmbitos fundamentais para o exercício e desenvolvimento da convivência. Trata-se de criar em cada escola espaços nos quais o conteúdo e o que contém estão ativamente implicados no desenvolvimento de boas práticas de convivência. Igualmente, partimos do facto de que o contexto organizativo em que se dão as práticas educativas é, ao mesmo tempo, meio e objeto de reflexão educativa. Em consequência, criar infraestruturas de convivênca significa desenhar aspetos relativos ao âmbito da escola e ao âmbito da aula (JARES, 2006, p. 97).

Uma outra forma de se perceber esta evolução na abordagem organizacional da Escola, consiste em concebê-la como um espaço social e pedagógico, que se destaca pelo complexo de interações sociais, nem sempre fácil de gerir. Logo, a Escola confronta-se com o cruzamento de culturas diversas, numa relação dinâmica de encontros e desencontros constantes. Trata-se de uma realidade que varia de escola para escola. Com efeito, perante o facto “[...] das dinâmicas de interação e os fenómenos disruptores assumirem contornos específicos e graus de intensidade diversos, suscitou-se a procura de novas pistas de compreensão no nível meso" (QUARESMA, 2010, p. 159).

A reflexão em torno do conflito e da convivência, dos modelos e métodos de tratamento de conflitos, assim como do papel da Escola por uma "educação a partir do conflito" (expressão utilizada por VINYAMATA, 2003), parece inaugurar um novo campo de estudo. Deste modo, a par do tradicional debate em torno do reforço da disciplina, pela via normativa, numa abordagem tecnocrática, relacionada com direitos e deveres, no contexto de um modelo impositivo e punitivo, surge um outro debate que questiona os 
modelos e lógicas da Escola na gestão dos conflitos, na regulação da convivência e, em sentido mais amplo, sobre o modelo de administração da justiça.

Em suma, mais do que procurar centrar a temática da gestão dos conflitos ao nível da interação entre alunos, ou entre alunos e professores, interessa deslocar essa preocupação para a própria organização escolar, envolvendo-a diretamente na abordagem desta problemática. A Escola não pode acolher ou oferecer projetos inovadores, excluindose dos processos de mudança. Como refere CANÁRIO (2010, p. 12), para as tensões e problemas sociais parece ter-se acreditado ser "[...] possível encontrar remédios sem colocar em causa a clássica gramática organizacional que marca a escola da modernidade”. Nesse sentido, para além daquilo que a Escola possa e deva oferecer, do ponto de vista educativo e social, aos seus alunos, ela mesma pode e deve reconhecer-se como uma organização que aprende e torna-se pilar estratégico da melhoria socioeducativa.

\section{O amplo alcance dos projetos de mediação de conflitos na escola}

Mais do que um programa de mediação de conflitos para alunos, comummente designado por programa de mediação entre pares (cadre program) advoga-se a implementação de projetos de mediação de conflitos de cariz amplo. Esta abordagem ampla dos projetos (whole approach), apresentada por FAGET (2010), consiste no envolvimento de toda a comunidade educativa na formação em mediação. Foi este, aliás, o modelo adotado, após 2005, na Finlândia. Trata-se de apostar na emergência de uma cultura de mediação que se enraíze na cultura escolar. Outra perspetiva da abordagem ampla dos programas de gestão e mediação de conflitos (whole programs) é proferida por ALZATE (2003), ao propor incluir as seguintes dimensões: sistema disciplinar; aspectos curriculares; aspectos metodológicos e pedagógicos (caso da aprendizagem cooperativa); cultura escolar e dimensão sociocomunitária. PINTO DA COSTA (2018) refere que uma intervenção ampla e sustentável, através de projetos de mediação, impõe que o envolvimento tanto dos indivíduos como da escola seja assumido como condição capital. A Escola é uma entidade de aprendizagem, capaz de inovar e, assim, acompanhar e apoiar a inovação proposta aos sujeitos que a constituem, numa coerência expressiva de valores, crenças, princípios e normas. Além dos indivíduos, interessa a Escola, detentora de uma cultura própria. Todos esses elementos fazem parte das dimensões do projeto de amplo alcance proposto pela autora: processual, interpessoal/social e organizacional. Estas três dimensões devem ser atendidas de forma articulada, como se se gerasse um fluxo de sinergias mútuas. Assim, 
pelo projeto de mediação de amplo alcance é possível desenvolver, de forma ordenada, contínua e persistente, uma reculturalização da cultura escolar que faça uma diferença positiva nos indivíduos, na escola e na sociedade (PINTO DA COSTA, 2018). Para isso, é ainda indispensável uma intervenção sistemática, coletiva e participada (PINTO DA COSTA, 2017). Desta forma, a Escola tende a tornar-se numa organização não só reativa mas também - e sobretudo- proativa e preventiva ao nível do tratamento dos conflitos, da indisciplina e da violência.

A mediação de conflitos no âmbito escolar é, neste sentido, uma metodologia de inovação social que visa potenciar uma convivência harmoniosa, democrática, inclusiva e cidadã, reforçando o papel da Escola como agente educativo e cultural nas comunidades em que se insere (PINTO DA COSTA, TORREGO e MARTINS, 2018).

\section{Considerações finais}

A argumentação teórica, sustentada numa metodológica de cariz qualitativo, visou reunir um conjunto de contributos analíticos sobre as categorias de análise definidas: conflito, convivência e mediação de conflitos no contexto das Ciências da Educação e da Escola atual.

A Escola contemporânea tem-se confrontado com inúmeras problemáticas sociais que a obrigaram a refletir sobre si mesma. Entre a tradição à qual a Escola se prende, do paradigma da instrução e a pressão de ser uma plataforma de mudança social, exigindo-selhe novas funções e novos papéis, que permitam atender à pluralidade de responsabilidades socioeducativas atribuídas, lança-se-lhe o complexo desafio da busca de novas e eficazes fórmulas de gestão do seu espaço social, relacional e cultural, numa lógica de socialização, de cidadania, de inclusão e de qualidade socioeducativa.

Contudo, as dissensões e as ruturas relacionais, que se revelam nos índices de indisciplina, de conflitualidade e de violência, constituem tanto uma fratura à normatividade escolar, como colocam em causa a cultura disciplinar, que se espera que aí exista. A necessidade de fomentar a convivência, pela gestão positiva das relações e dos conflitos tornou-se uma prioridade da Escola. Esta dimensão social assume-se também uma questão educativa, pedagógica e organizacional.

Em face dessa relevância do tema, o estudo sobre o conflito e a convivência tem-se afirmado no campo da sociologia da Escola, centrando-se nas suas caraterísticas organizacionais e estendendo-se do nível de análise micro (sala de aula) para um nível 
meso, onde a própria Escola é objeto de estudo e de intervenção. Reconhece-se que qualquer intervenção melhoria socioeducativa deve influir ao nível da sua cultura organizacional - nas conexões e relações decorrentes das normas, das práticas, dos valores e das crenças partilhados pelos indivíduos (BARROSO, 2005).

Os projetos de mediação de conflitos na escola afiguram-se como dispositivos de intervenção de melhoria de convivência nas escolas. As críticas denunciaram, no entanto, que este tipo de iniciativas carecia de uma dimensão orgânico-cultural, que alicerçasse a mediação em várias dimensões da organização e lhe conferisse amplitude e sustentabilidade. Em suma, os projetos de mediação de conflitos em contexto escolar devem assentar em quatro vertentes: a) técnica de intervenção na gestão e resolução de conflitos; b) metodologia integrada de prevenção: primária, secundária e terciária; c) ferramenta de desenvolvimento pessoal e social; d) estratégia de melhoria orgânico-cultural. Ora, dadas as exigências inerentes à implementação destes projetos, requerem--se mudanças, tanto a nível interpessoal, como a nível organizacional. Trata-se de uma intervenção em que indivíduos e organização apre(e)ndem novos procedimentos, usufruem de novas estruturas e beneficiam de processos promotores de qualidade socioeducativa.

\section{Notas}

(1) Recomendação sobre a educação para a compreensão e a paz internacionais e a educação relativa aos direitos humanos e liberdades fundamentais, adotada pela Organização das Nações Unidas para a Educação, Ciência e Cultura, em 1974. A resolução 52/243, adotada pela Assembleia Geral das Nações Unidas, em 1999, declara a cultura de paz. A resolução 52/15, adotada pela UNESCO, em 2000, declara a década internacional para a cultura de paz e não violência. A resolução 53/15, adotada pela UNESCO, em 2000, declara a década internacional para a cultura de paz e não violência para com as crianças. O Manifesto 2000 por uma cultura de paz e não violência, elaborado por personalidades laureadas com o Prémio Nobel da Paz, em conjunto com a ONU e a UNESCO.

(2) Carta do Conselho da Europa sobre a educação para uma cidadania democrática e a educação para os direitos humanos, de 2010.

(3) Esta questão está espelhada nos Objetivos para o Desenvolvimento Sustentável, contidos na Agenda 2030 para o Desenvolvimento Sustentável das Nações Unidas, mais especificamente no objetivo 4, intitulado "garantir uma educação de qualidade inclusiva e equitativa", que estabelece como meta a atingir até 2030, a aquisição por todos os alunos de conhecimentos e habilidades necessários para promover o desenvolvimento sustentável, incluindo, entre outros, através da educação para os direitos humanos, a igualdade de género, a promoção de uma cultura de paz e não-violência, uma cidadania global e a valorização da diversidade cultural. Nações Unidas (2015). Transformar o nosso mundo: A Agenda 2030 para o Desenvolvimento Sustentável (A/70/L.1). Acedido em http://www.un.org/ga/search/view doc.asp?symbol=A/70/L.1\&Lang=S

(4) O relatório da Comissão Europeia, de 2018, ressalva a importância de sensibilizar os aprendentes e o pessoal educativo para a importância da aquisição de competências essenciais para a sua relação com a sociedade. Recomendação sobre as Competências Essenciais para a Aprendizagem ao Longo da Vida. Dossiê interinstitucional: 2018/0008 (NLE). Acedido em https://eur-lex.europa.eu/legalcontent/PT/TXT/PDF/?uri=CONSIL:ST 90092018 INIT\&from=EN 


\section{Referências}

ALZATE, Ramón. Resolución de conflictos. Transformación de la escuela. In Eduard Vinyamata (Coord.), Aprender del conflicto. Conflicto e educación (pp. 51-64). Barcelona: Graó, 2003.

AMADO, João e FREIRE, Isabel. $A(s)$ Indisciplina(s) na Escola - Compreender para Prevenir. Coimbra: Almedina, 2009.

BARROSO, João. Politicas Educativas e Organização Escolar. Lisboa: Livraria Universidade Aberta, 2005.

BOLÍVAR, António. Como melhorar as escolas. Estratégias e dinâmicas de melhoria das práticas educativas. Porto: Asa, 2003.

BOLÍVAR, António. Los centros educativos como organizaciones que aprenden. Madrid: La Muralla, 2000.

BRANDONI, Florencia. Mediación escolar, un aporte a la convivencia. In M. Flores; Assunção Silva e Sandra Fernandes (Orgs.), Contextos de mediação e de desenvolvimento profissional (pp. 59-77). Santo Tirso: De Facto, 2018.

CANÁRIO, Rui. Prefácio. In Vitor Almeida, O mediador sócio-cultural em contexto escolar. Contributos para a compreensão da sua função social. Mangualde: Edições Pedago, 2010.

CUNHA, Pedro e MONTEIRO, Ana. Gestão de Conflitos na Escola. Lisboa: Pactor, 2018.

FAGET, Jacques. Médiations. Les ateliers silencieux de la démocratie. Toulouse: Érès, 2010.

FLICK, Uwe. Métodos Qualitativos na Investigação Cientifica. Lisboa: Monitor, 2005.

GIMÉNEZ, Carlos. Convivencia. Conceptualización y sugerencias para la praxis. Puntos de vista: Cuadernos del Observatorio de las migraciones y la convivencia intercultural de la cuidad de Madrid (oMci), 2005, 1, 7-31. Disponível em http://dialnet.unirioja.es/servlet/ejemplar?codigo=176976. Acesso em abril de 2019.

JARES, Xesus. Pedagogía de la convivencia. Barcelona: Graó, 2006.

JARES, Xesus. Educação e conflito. Guia de educaşão para a convivência. Porto: Asa, 2002.

JARES, Xesus. El lugar del conflicto en la organización escolar. Revista Iberoamericana de Educación, 1997 15, set-dez, 53-73. Disponível em http://www.rieoei.org/oeivirt/rie15a02.htm. Acesso em março de 2019.

NÓVOA, António. Para uma análise das Instituições Escolares, $2^{a}$ ed. In A. Nóvoa, (Org.), As organiz̧ações escolares em análise (pp. 13-43). Lisboa: Publicações Dom Quixote, 1995.

PINTO DA COSTA, Elisabete e SÁ, Susana. Teacher Narratives on the Practice of Conflict Mediation. António Costa, Luís Reis e António Moreira (Eds.), Computer Supported Qualitative Research - New Trends on Qualitative Research. WCQR2018. Advances in Intelligent Systems and Computing, vol 861, (pp. 156-169). Springer: Switzerland, 2019. 
PINTO DA COSTA, Elisabete; TORREGO, Juan e MARTINS, Alcina. Mediação escolar: a análise qualitativa da dimensão interpessoal/ social de um projeto de mediação. Revista Lusófona de Educaşão, 2018, 40, 111-126.

PINTO DA COSTA, Elisabete. Modelos de mediación de conflictos en el ámbito escolar y evidencias de un proyecto portugués con un enfoque amplio. In Juan Torrego; Laura Rayón; Y. Muñoz \& P. Hernández (Eds.), Inclusión y Mejora Educativa. Obras colectivas. Ciencias de la educación, 24 (pp. 228-238). Alcalá de Henares: Servicio de Publicaciones de Universidad de Alcalá de Henares, 2018.

PINTO DA COSTA, Elisabete. Um projeto de mediação de conflitos: facilitadores, condicionantes e melhorias. Revista de Estudios e Investigación en Psicología y Educación, 2017, Vol. Extr., No. 02, 95-100.

QUARESMA, Luísa. Interação e indisciplina na escola. In Pedro Abrantes (Org.), Tendências e controvérsias em sociologia da educação (pp. 159-171). Lisboa: Mundos Sociais, 2010.

SANCHES, Maria. A Escola como espaço social (leituras e olhares de professores e alunos). Porto: Porto Editora, 2009.

TORRES, Leonor e PALHARES, José. Organizações Escolares. Um croqui sociológico sobre a investigação portuguesa. In Pedro Abrantes (Org.), Tendências e controvérsias em Sociologia da Educação (pp. 133-158). Lisboa: Mundos Sociais, 2010.

TORREGO, Juan. Modelo integrado de mejora de la convivencia. Estrategias de mediación y tratamiento de conflictos. Barcelona: Graó, 2006.

VINYAMATA, Eduard. Aprender del conflicto. Conflictología y educación. Barcelona: Graó, 2003.

Recebido em: 15 abr. 2019 / Aprovado em: 25 jun. 2019

\section{$\underline{\text { Cite como }}$}

COSTA, Elisabete Guedes Pinto da. A escola como entidade promotora de melhoria da convivência, através da mediação de conflitos, no contexto das ciências da educação. Dialogia, São Paulo, n. 32, p. 81-92, maio/ago. 2019. Disponível em: https://doi.org/10.5585/Dialogia.n32.13636. 